\title{
Правила или традиции - основа для номенклатуры минералов группы трифилина
}

Лялина Л.М. ${ }^{1}$, Селиванова Е.А. ${ }^{1,2}$, Золотарев А.А. (мл.) ${ }^{3}$, Савченко Е.Э. ${ }^{1,2}$

${ }^{1}$ Геологический институт КНЦ РАН, Anamumbl, lialina@geoksc.apatity.ru

${ }^{2}$ Центр наноматериаловедения ФИЦ КНЦ РАН, Anamumbl, selivanova@geoksc.apatity.ru; evsav@geoksc.apatity.ru

${ }^{3}$ Санкт-Петербургскийгосударственный университет, Институт науко Земле, Санкт-Петербург, aazolotarev@gmail.com

Аннотация. Взамен исторически сложившемуся разделению промежуточных по составу фосфатов с оливиновым типом структуры на минеральные виды по косвенным признакам (ассоциация, оптические характеристики) предложена классификация, основанная на определяющих (конституционных) свойствах минералов - химическом составе и кристаллической структуре. Определены границы составов $\mathrm{Li}(\mathrm{Fe}, \mathrm{Mn})$-фосфатов группы трифилина с общей формулой $\left(\mathrm{A}^{+}{ }_{x}, \square_{1-x}\right)\left(\mathrm{B}^{2+}{ }_{x}, \mathrm{C}^{3+}{ }_{1-x}\right)\left(\mathrm{PO}_{4}\right)$, где $\mathrm{x}=0,0.5$ или $1 ; \mathrm{A}=\mathrm{Li} ; \mathrm{B}^{2+}\left(\mathrm{C}^{3+}\right)=\mathrm{Mn}, \mathrm{Fe}$. Приведена номенклатура $\mathrm{Li}(\mathrm{Fe}, \mathrm{Mn})$-фосфаты группы трифилина, в рамках которой установленные в сподуменовых пегматитах Колмозерского месторождения минералы диагностированы как литиофилит (светлый тип) и феррисиклерит (бурый и черный типы).

Ключевые слова: $\mathrm{Li}(\mathrm{Fe}, \mathrm{Mn})$-фосфаты, группа трифилина, минеральный вид, номенклатура, сподуменовые пегматиты, Колмозерское литиевое месторождение, Арктика.

\section{Rules and traditions as a foundation for nomenclature of the triphylite group minerals}

Lyalina L.M. ${ }^{1}$, Selivanova E.A. ${ }^{1,2}$, Zolotarev A.A. (jr) ${ }^{3}$, Savchenko Ye.E. ${ }^{1,2}$

${ }^{1}$ Geological Institute FRC KSC RAS, Apatity, lialina@geoksc.apatity.ru

2 Nanomaterials Research Center KSC RAS, Apatity, selivanova@geoksc.apatity.ru; evsav@geoksc.apatity.ru 3 Saint Petersburg state University, Institute of Earth Sciences, Saint Petersburg,evsav@geoksc.apatity.ru

Abstract. Instead of the historically established classification of the intermediate olivine-type phosphates into mineral species based on indirect features (association, optical features), we offer a classification based on defining (constitutive) mineral features, i.e., their chemical composition and crystal structure. Compositions of the triphylite group $\mathrm{Li}(\mathrm{Fe}, \mathrm{Mn})$-phosphates with the general formula $\left(\mathrm{A}^{+}, \square_{1-x}\right)\left(\mathrm{B}^{2+}{ }_{x}, \mathrm{C}^{3+}{ }_{1-x}\right)\left(\mathrm{PO}_{4}\right)$, where $\mathrm{x}=0,0.5$ or 1 , and $\mathrm{A}=\mathrm{Li}$; $\mathrm{B}(\mathrm{C})=\mathrm{Mn}, \mathrm{Fe}$ have been specified. A nomenclature of the triphylite group $\mathrm{Li}(\mathrm{Fe}, \mathrm{Mn})$-phosphates, within which minerals found in spodumene pegmatites of the Kolmozero deposit have been diagnosed as lithiophilite (light type) and ferrisicklerite (brown and black types), is provided.

Key words: $\mathrm{Li}(\mathrm{Fe}, \mathrm{Mn})$-phosphates, triphylite group, mineral species, nomenclature, spodumene pegmatites, Kolmozero lithium deposit, Arctics.

\section{Введение}

Лавинообразный рост исследований и публикаций, посвященных $\mathrm{Li}(\mathrm{Fe}, \mathrm{Mn})$-фосфатам со структурой оливинового типа произошел после открытия уникальных электрохимических свойств трифилина, которые и объясняют статус минералов как «наилучшего материала для катодов в электрических батареях» (Hatert, 2012а и ссылки в этой работе).

Традиционно считается, что в процессе окисления железа и марганца и сопутствующему ему выносу лития трифилин $\mathrm{LiFe}^{2+}\left(\mathrm{PO}_{4}\right)$ и литиофилит $\mathrm{LiMn}^{2+}\left(\mathrm{PO}_{4}\right)$ через промежуточные фазы - феррисиклерит и сиклерит, превращаются в гетерозит $\mathrm{Fe}^{3+}\left(\mathrm{PO}_{4}\right)$ и пурпурит $\mathrm{Mn}^{3+}\left(\mathrm{PO}_{4}\right)$. Данная схема изоморфных замещений $\mathrm{Li}^{+}\left(\mathrm{Fe}^{2+}, \mathrm{Mn}^{2+}\right) \leftrightarrow \square\left(\mathrm{Fe}^{3+}, \mathrm{Mn}^{3+}\right)$ под названием «последовательности КвенселаМэйсона (Quensel - Mason)» прочно вошла в литературу (Schmid-Beurmann et al., 2013, Baijot et al., 2012 и др.). 
Несмотря на простой химический состав и такую же простую схему изоморфизма, диагностика минеральных видов и проведение границ между ними вызывают затруднения, причиной которых являются, отчасти, сложности в химическом анализе вещества. Разделение $\mathrm{Li}(\mathrm{Fe}, \mathrm{Mn})$-фосфатов с оливиновым типом структуры на минералы часто проводят по косвенным признакам: оптическим характеристикам (Fontan et al., 1976, Roda-Robles et al., 2014) или минеральным ассоциациям (Roda et al., 2004). Такой подход, конечно, не является приемлемым, минерал должен диагностироваться по определяющим (конституционным) свойствам - кристаллической структуре и химическому составу.

В качестве примеров, поясняющих проблему номенклатуры, можно привести: одинаковые формулы литиофилита и сиклерита (IMA List of Minerals, January 2021), отсутствие критериев (границ) между минеральными видами. Не имея систематики и номенклатуры рассматриваемых фосфатов, исследователи вынуждены либо использовать двойные названия минерала - «литиофилитсиклерит» (Hatert et al., 2011), либо вовсе оставлять минерал не диагностированным до вида (Roda-Robles et al., 2014). Надо отметить, что проблема номенклатуры фосфатов с оливиновым типом структуры в целом, и вопрос границы между литиофилитом и сиклеритом, в частности, уже поднимались (Hatert et al., 2012 b).

С подобными сложностями определения минералов столкнулись и авторы при изучении $\mathrm{Li}(\mathrm{Fe}, \mathrm{Mn})$-фосфатов с отношениями $\mathrm{Fe}: \mathrm{Mn} \approx 1: 1$ (Лялина и др., 2020). Комбинируя данные микрозондовых анализов и монокристальных исследований (Золотарев и др., 2020), были рассчитаны эмпирические формулы разновидностей «трифилинов» из сподуменовых пегматитов Колмозера:

$$
\begin{aligned}
& \text { - светлый }\left(\mathrm{Li}_{0.91} \square_{0.09}\right)_{1.00}\left(\mathrm{Mn}^{2+}{ }_{0.62} \mathrm{Fe}^{2+}{ }_{0.33} \mathrm{Fe}^{3+}{ }_{0.09} \mathrm{Mg}_{0.01} \mathrm{Ca}_{0.01}\right)_{1.06} \mathrm{P}_{1.00} \mathrm{O}_{4} ; \\
& \text { - бурый }\left(\mathrm{Li}_{0.63} \square_{0.37}\right)_{1.00}\left(\mathrm{Mn}^{2+}{ }_{0.65} \mathrm{Fe}^{3+}{ }_{0.26} \mathrm{Mn}^{3+}{ }_{0.11} \mathrm{Mg}_{0.02} \mathrm{Ca}_{0.01}\right)_{1.05}\left(\mathrm{P}_{0.99} \mathrm{Si}_{0.01}\right)_{1.00} \mathrm{O}_{4} \text {; } \\
& \text { - черный }\left(\square_{0.58} \mathrm{Li}_{0.42}\right)_{1.00}\left(\mathrm{Fe}^{3+}{ }_{0.50} \mathrm{Mn}^{2+}{ }_{0.44} \mathrm{Mn}^{3+}{ }_{0.08} \mathrm{Mg}_{0.02} \mathrm{Ca}_{0.01}\right)_{1.05} \mathrm{P}_{1.00} \mathrm{O}_{4 .}
\end{aligned}
$$

Определение светлой разновидности как литиофилита не вызывает затруднений, чего нельзя сказать про бурую и черную разновидности.

\section{Диаграммы для классификации Li(Fe,Mn)-фосфатов группы трифилина}

Li(Fe,Mn)-фосфаты со структурой оливинового типа (Finger, Rapp, 1969; Якубович и др., 1977) из группы трифилина имеют стандартную формулу $M 1 M 2 T \mathrm{O}_{4}$, где $M 1(\mathrm{Li})$ и $M 2(\mathrm{Fe}, \mathrm{Mn})$ - октаэдрические, а $T(\mathrm{P})$ - тетраэдрические катионы.

Изучение продуктов окисления $\mathrm{Li}(\mathrm{Fe}, \mathrm{Mn})$-фосфатов в природных образцах, а также экспериментальные данные (Murdoch, 1955; Roda et al., 2004; Schmid-Beurmann et al., 2013 и др.) позволяют предположить, что первым в этих фосфатах окисляется железо, а окисление марганца начинается только после полного перехода железа в $\mathrm{Fe}^{3+}$. Отсюда следуют ограниченные варианты сочетания катионов в позиции $M 2: 1) \mathrm{Fe}^{2+}, \mathrm{Mn}^{2+}, \mathrm{Fe}^{3+}$ и 2) $\mathrm{Mn}^{2+}, \mathrm{Fe}^{3+}, \mathrm{Mn}^{3+}$, что позволяет наносить составы минералов на обычные треугольные диаграммы (рис. 1, а). Треугольники имеют общую сторону $\mathrm{Mn}^{2+}-\mathrm{Fe}^{3+}$, по которой могут быть совмещены (рис. 1, б). Мы получаем диаграмму (рис. 1, в), учитывающую все катионы в позиции $M 2$ и подобную диаграмме в работе (Fontan et al., 1976).

\section{Классификация и номенклатура по правилам Международной минералогцческой ассоциации (IMA)}

Строго следуя правилу выделения минералов в сериях твердых растворов по доминирующему компоненту и доминирующей валентности (Hatert, Burke, 2008), границы между минеральными видами следует провести так, как показано на рисунке 1, г. Самостоятельными минеральными видами могут считаться только конечные члены серий твердых растворов - трифилин, литиофилит, гетерозит и пурпурит (рис. 1, г). В то время как феррисиклерит и сиклерит должны быть дискредитированы. В этом случае общая формула $\mathrm{Li}(\mathrm{Fe}, \mathrm{Mn})$-фосфатов группы трифилина имеет вид $\left(\mathrm{A}^{+}{ }_{1-\mathrm{x}} \square_{\mathrm{x}}\right)$ $\left(\mathrm{B}^{2+}{ }_{1-\mathrm{x}} \mathrm{C}_{\mathrm{x}}^{3+}\right)\left(\mathrm{PO}_{4}\right)$, где $\mathrm{x}=0$ или $1, \mathrm{~A}^{+}=\mathrm{Li} ; \mathrm{B}^{2+}\left(\mathrm{C}^{3+}\right)=\mathrm{Fe}, \mathrm{Mn}$. В группу войдут: трифилин $\mathrm{LiFe}^{2+}\left(\mathrm{PO}_{4}\right)$, литиофилит $\mathrm{LiMn}^{2+}\left(\mathrm{PO}_{4}\right)$, гетерозит $\mathrm{Fe}^{3+}\left(\mathrm{PO}_{4}\right)$, пурпурит $\mathrm{Mn}^{3+}\left(\mathrm{PO}_{4}\right)$. 

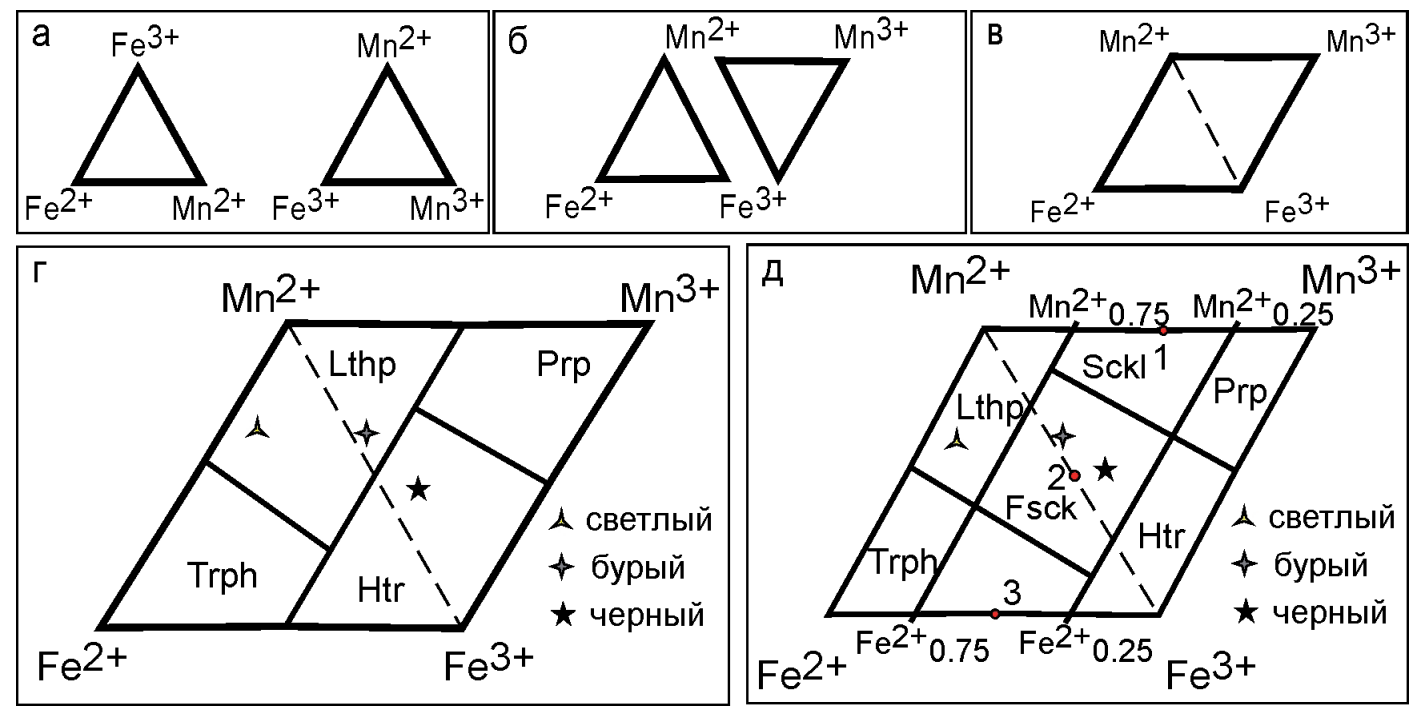

Рис. 1. Классификационные диаграммы для Li(Fe,Mn)-фосфатов с оливиновым типом структуры. Сокращения: Trph - трифилин, Lthp - литиофилит, Prp - пурпурит, Htr - гетерозит, Sckl - сиклерит, Fsck - феррисиклерит.

Fig. 1. Diagrammatic representations of heterovalent substitutions in olivine-type Li(Fe,Mn)-phosphates. Abbreviations: Trph - triphylite, Lthp - lithiophilite, Prp - purpurite, Htr - heterosite, Sckl - sicklerite, Fsck - ferrisicklerite.

Изученные фосфаты из сподуменовых пегматитов Колмозеро попадают в поля литиофилита (светлый и бурый) и гетерозита (черный) (рис. 1, г).

\section{Классификация и номенклатура с сохранением утвержденных (традиционных) минеральных видов}

Сохранение минеральных видов феррисиклерита и сиклерита может быть целесообразным из практических соображений. Увеличение содержания трехвалентных катионов приводит к существенным изменениям физических свойств, в частности оптических, поэтому использование исторически укоренившихся названий «феррисиклерит» и «сиклерит» вполне оправдано. Однако следует навести порядок с классификацией и номенклатурой фосфатов оливинового типа, хотя при этом придется отступить от строгого следования правилу 50 \% содержания компонента.

На серединах линий, соответствующих сериям твердых растворов, располагаются точки промежуточных составов (рис. 1 , д). На линии $\mathrm{Mn}^{2+}$ (литиофилит) - $\mathrm{Mn}^{3+}$ (пурпурит) располагается точка 1 с формулой $\left(\mathrm{Li}_{0.5} \square_{0.5}\right)\left(\mathrm{Mn}^{2+}{ }_{0.5} \mathrm{Mn}^{3+}{ }_{0.5}\right)\left(\mathrm{PO}_{4}\right)$, на линии $\mathrm{Mn}^{2+}$ (литиофилит) - $\mathrm{Fe}^{3+}$ (гетерозит) - точка 2 с формулой $\left(\mathrm{Li}_{0.5} \square_{0.5}\right)\left(\mathrm{Mn}^{2+}{ }_{0.5} \mathrm{Fe}^{3+}{ }_{0.5}\right)\left(\mathrm{PO}_{4}\right)$, на линии $\mathrm{Fe}^{2+}$ (трифилин) - $\mathrm{Fe}^{3+}$ (гетерозит) - точка 3 с формулой $\left(\mathrm{Li}_{0.5} \square_{0.5}\right)\left(\mathrm{Fe}^{2+}{ }_{0.5} \mathrm{Fe}^{3+}{ }_{0.5}\right)\left(\mathrm{PO}_{4}\right)$ (рис. 1, д). Эти точки, отступая от правил IMA, могут быть приняты за самостоятельные минеральные виды: 1 - сиклерит, 2 - феррисиклерит, 3 - гипотетическая фаза без названия. Тогда границами между минеральными видами будут линии $\mathrm{Fe}^{2+}{ }_{0.25}-\mathrm{Mn}^{2+}{ }_{0.25}, \mathrm{Fe}^{2+}{ }_{0.75}-\mathrm{Mn}^{2+}{ }_{0.75}$ и продолжение границ трифилин-литиофилит и гетерозит-пурпурит (рис. 1, д).

Сохраняя самостоятельными минеральные виды промежуточных составов, общую формулу $\mathrm{Li}(\mathrm{Fe}, \mathrm{Mn})$-фосфатов группы трифилина можно записать как $\left(\mathrm{A}^{+}{ }_{1-\mathrm{x}} \square_{\mathrm{x}}\right)\left(\mathrm{B}^{2+}{ }_{1-\mathrm{x}} \mathrm{C}^{3+}{ }_{\mathrm{x}}\right)\left(\mathrm{PO}_{4}\right)$, где $\mathrm{x}=0.0 .5$ или $1, \mathrm{~A}^{+}=\mathrm{Li} ; \mathrm{B}^{2+}\left(\mathrm{C}^{3+}\right)=\mathrm{Mn}, \mathrm{Fe}$. Формулы минералов следующие (для промежуточных составов формулы удвоены во избежание дробных коэффициентов): $\mathrm{LiFe}^{2+} \mathrm{PO}_{4}$ - трифилин, $\mathrm{LiMn}^{2+} \mathrm{PO}_{4}$ - литиофилит, $\mathrm{Fe}^{3+} \mathrm{PO}_{4}$ - гетерозит, $\mathrm{Mn}^{3+} \mathrm{PO}_{4}$ - пурпурит, $\mathrm{Li}\left(\mathrm{Mn}^{2+}, \mathrm{Fe}^{3+}\right)_{2}\left(\mathrm{PO}_{4}\right)_{2}-$ феррисиклерит, $\mathrm{Li}\left(\mathrm{Mn}^{2+}, \mathrm{Mn}^{3+}\right)_{2}\left(\mathrm{PO}_{4}\right)_{2}$ - сиклерит.

Из общей формулы следуют еще два возможных сочетания элементов. Гипотетический $\mathrm{Li}\left(\mathrm{Fe}^{2+}, \mathrm{Fe}^{3+}\right)_{2}\left(\mathrm{PO}_{4}\right)_{2}$, существование которого вероятно, и $\mathrm{Li}\left(\mathrm{Fe}^{2+}, \mathrm{Mn}^{3+}\right)_{2}\left(\mathrm{PO}_{4}\right)_{2}$, существование которого невозможно, если принимать полное окисление железа вперед марганца.

Минералы из Колмозера попадают в поля феррисиклерита (бурый и черный типы) и литиофилита (светлый тип) (рис. 1, д). 
Следует отметить, что в данном варианте классификации и номенклатуры $\mathrm{Li}(\mathrm{Fe}, \mathrm{Mn})$-фосфатов с оливиновым типом структуры, сохраняемые в качестве самостоятельных минеральные виды (сиклерит, феррисиклерит) имеют широкие вариации составов. Особенно это касается феррисиклерита. К нему относятся как полнокатионные (apfu $\mathrm{Li}>0.5$ ), так и катиондефицитные минералы $($ apfu $\mathrm{Li}<0.5)$, марганцевые ( apfu $\mathrm{Mn}^{2+}>$ apfu $\mathrm{Fe}^{2+}$ ) и железистые $\left(a p f u \mathrm{Fe}^{2+}>\right.$ apfu $\mathrm{Mn}^{2+}$ ) разновидности. Но, тем не менее, порядка в группе трифилина будет больше, а сложностей с определением минерального вида меньше.

\section{Заключение}

Строгое следование правилам IMА выделения минеральных видов в сериях твердых растворов однозначно определяет формулы минералов и границы между ними. Но требует отказа от утвержденных феррисиклерита и сиклерита, являющихся исторически укоренившимися названиями, традиционно используемыми для обозначения продуктов изменения трифилина-литиофилита.

Сохранение феррисиклерита, сиклерита и подобного им промежуточного по составу симферита, делает классификацию и номенклатуру более сложными, вводя дополнительные границы между минералами. Кроме того, в пределах одного минерального вида, объединяются фазы, существенно различающиеся составами и, соответственно, эмпирическими формулами, как это было показано на примере феррисиклерита.

Несмотря на это, авторы считают возможным такой вариант номенклатуры группы трифилина, поскольку достаточно распространенные промежуточные по составу фазы существенно отличаются по свойствам от крайних членов рядов. Изученные $\mathrm{Li}(\mathrm{Fe}, \mathrm{Mn})-$ фосфаты из сподуменовых пегматитов Колмозера, Кольский полуостров, Россия авторы определяют как литиофилит и две разновидности феррисклерита.

Работа выполнена в рамках темы НИР №0226-2019-0051.

\section{Литература}

1. Золотарев А.А. (мл.), Кудряшов Н.М., Селиванова Е.А., Савченко Е.Э., Лялина Л.М. Кристаллическая структура минералов группы трифилина из сподуменовых пегматитов Колмозерского месторождения, Кольский полуостров // Труды Ферсмановской научной сессии ГИ КНЦ РАН. 2020. 17. С. 201-206. doi.org/10.31241/FNS.2020.17.037.

2. Лялина Л.М., Кудряшов Н.М., Селиванова Е.А., Савченко Е.Э. Минералы группы трифилина из сподуменовых пегматитов Колмозерского месторождения (Кольский полуостров) // Труды Ферсмановской научной сессии ГИ КНЦ РАН. 2020. 17. С. 339-343. doi.org/10.31241/FNS.2020.17.064.

3. Якубович О.В., Симонов М.А., Белов Н.В. Кристаллическая структура синтетического трифилина $\mathrm{LiFe}\left[\mathrm{PO}_{4}\right] / /$ ДАН СССР. 1977. 235. 1. С. 93-95.

4. Baijot M., Hatert F., Philippo S. Mineralogy and geochemistry of phosphates and silicates in the Sapucaia pegmatite, Minas Gerais, Brazil: genetic implications // The Canadian Mineralogist. 2012. N. 50(6). P. 1531-1554. DOI: $10.3749 /$ canmin.50.6.1531.

5. Finger L.W., Rapp G.R. Refinement of the crystal structure of triphylite. Carnegie Institute Washington Yearbook. 1969. V. 68. P. 290-292.

6. Fontan P.F., Huvelin P., Orliac M., Permingeat F. La ferrisicklérite des pegmatites de Sidi Bou Othmane (Jebilet, Maroc) et le groupe des minéraux à structure de triphylite // Bulletin de la Société Française de Minéralogie et de Cristallographie. 1976. 99. P. 274-286.

7. Hatert F., Burke E. THE IMA-CNMNC dominant-constituent rule revisited and extended // The Canad. Mineral. 2008. V. 46(3). P. 717-728.https://doi.org/10.3749/canmin.46.3.717.

8. Hatert F., Ottolini L., Schmid-Beurmann P. Experimental investigation of the alluaudite+triphylite assemblage, and development of the Na-in-triphylite geothermometer: applications to natural pegmatite phosphates // Contrib. Mineral. Petrol. 2011. V. 161. P. 531-546. DOI 10.1007/s00410-010-0547-6.

9. Hatert F. Iron-Manganese Phosphates with the Olivine - and Alluaudite-Type Structures: Crystal Chemistry and Applications // In: Minerals as Advanced Materials II. Sergey V. Krivovichev ed. Springer Heidelberg New York Dordrecht London. 2012a. 427 p. DOI 10.1007/978-3-642-20018-2.

10. Hatert F., Ottolini L., Wouters J., Fontan F. A structural study of the lithiophilite-sicklerite series // The Canad. Mineral. 2012 b. V. 50. P. 843-854.

11. Murdoch J. Phosphate minerals of the Borborema pegmatites: I-Patrimonio // Amer. Mineral. 1955. V. 40. P. 50-63. 
12. Roda E., Pesquera A., Fontan F., Keller P. Phosphate mineral associations in the Cañada pegmatite (Salamanca, Spain): Paragenetic relationships, chemical compositions, and implications for pegmatite evolution // Amer. Mineral. 2004. V. 89. P. 110-125.

13. Roda-Robles E., Pesquera A., García de Madinabeitia S., Gil Ibarguchi J., Nizamoff J., Simmons W., Falster A., Galliski M.A. On the geochemical character of primary Fe-Mn phosphates belonging to the triphylitelithiophilite, graftonite-beusite, and triplite-zwieselite series: first results and implications for pegmatite petrogenesis // The Canad. Mineral. 2014. 52. P. 321-335. DOI: 10.3749/canmin.52.2.321.

14. Schmid-Beurmann P., Ottolini L., Hatert F., Geisler T., Huyskens M., Kahlenberg V. Topotactic formation of ferrisicklerite from natural triphylite under hydrothermal conditions // Mineralogy and Petrology. 2013. V. 107. P. 501-515. DOI 10.1007/s00710-012-0250-6. 